\title{
Latent Nuclear Antigen Antibody
}

National Cancer Institute

\section{Source}

National Cancer Institute. Latent Nuclear Antigen Antibody. NCI Thesaurus. Code C120478.

Any immunoglobulin that recognizes the human herpesvirus 8 latent nuclear antigen protein. 